\title{
Dynamic value networks: an insightful way to represent value exchanges in fast-moving industries
}

\author{
Jonathan Spruytte, Bavo Devocht, Marlies Van der Wee, Sofie Verbrugge, Didier Colle \\ Ghent University - imec, IDLab, Department of Information Technology \\ iGent Tower - Department of Information Technology \\ Technologiepark-Zwijnaarde 15, B-9052 Ghent, Belgium \\ \{jonathan.spruytte, bavo.devocht, marlies.vanderwee, sofie.verbrugge, didier.colle\}@ugent.be
}

\begin{abstract}
In order to survive in a fast-moving, competitive market, a lot of companies constantly have to re-innovate and rethink their business model; this might also include changing key partners. The interactions between these partners, and the exchange of goods, services, money or knowledge, so called value flows, are modeled using value networks. Existing models to represent value networks typically use a static approach, representing only a fixed point in time, missing the ability to show long-term effects and evolutions. This paper clearly defines the concept of dynamic value network (DVN) configurations and suggests a uniform representation based upon a time-oriented approach which will help companies to estimate the impact of future business decisions. This approach was implemented in a prototype and applied to a real-life use case to show the strength of the proposed concept.
\end{abstract}

Keywords-dynamic value network; techno-economics, business modelling

\section{INTRODUCTION}

Companies are under constant pressure to re-innovate their own business model: in a lot of markets competition is really fierce and the only way to stay on top is by continuous progress and change. This is especially true in the telecom world; less than 30 years ago, everyone was looking at broadcast TV and the only method for voice calls were fixed line telephones, while now a life without the large range of VOD (Video on Demand) and OTT (Over The Top) communications services is unthinkable.

Implementing a new, long-term, business strategy typically means changing the business model, this can imply changing internal and external processes, targeting different markets or linking up with new key partners. As a result, other companies will be impacted too; new contracts are negotiated resulting in new exchanges of goods, services, money or knowledge. These exchanges are known as value streams and are grouped in value networks (VN), and visualized using various models, each witch specific goals and representations. These models however are typically a fixed representation: they represent value streams between the relevant roles or partners for a single point in time, meaning they cannot be used to visualize any (long-term) effect the anticipated changes will have on the value network.

This paper goes beyond a static representation by defining the concept of a dynamic value network (DVN) and its uniform representation. These dynamic value networks can be used to represent a value network for multiple points in time, effectively visualizing the impact of major strategic decisions. The remainder of this work is structured as follows: In section II we discuss the commonly used models for representing value exchanges between different actors. Next, section III discusses the most important parameters that were found in these existing models and that should be implemented in DVN-models. Afterwards in section IV, we introduce the newly developed DVN-approach, including the implementation of these relevant parameters, followed by two examples in section V. Finally, section VI concludes this publication and discusses a number of future tracks.

\section{ANALYSIS OF EXISTING MODELS}

Different frameworks have been developed for representing the interaction between different companies; the most important ones are discussed in this section. Important to know is that different models have different goals and may have specific uses. For that very reason, models that only focus upon a single actor are omitted in this overview (such as the resources-events-agents [1], Value Stream Mapping [2] and Service-Oriented Business Architecture analysis [3]).

Generally, in order to apply any of the considered models, having a profound knowledge of how the company operates, both now and if applicable the considered future time span, is required: e.g. the different transactions which are modeled using Value Network Analysis in paragraph B; additionally, having insider information about cost and revenues might be required: e.g. for the definition of the value streams in Value Delivery Modeling language in paragraph D.

\section{A. Business Model Canvas (BMC)}

The BMC has been created to simplify the development and analysis of (new) business models; it consists of a formal description of 9 building blocks within a business model: customer segments, key activities, revenue streams, value propositions, channels, customer relationships, key resources, cost structures and key partnerships. These building blocks were initially described in [4] and later transformed in the business model canvas [5]. The BMC clearly defines the (possible) key partners within a VN, though does not explicitly define the value flows between the segments, nor 
does it define the value streams between external partners; it is hence actor-centered.

\section{B. Value Network Analysis (VNA)}

VNA, as presented by Allee [6], takes a whole different approach compared to the $\mathrm{BMC}$; it focuses on the exchange ("transaction") of value ("things" or "deliverables") between roles ("participants"), which can both be tangible or intangible. The value network is represented in a graph in which the nodes are the actors and the edges are the exchanges. This approach is clearly network-centered, focusing upon the interactions between the roles, as shown in Figure 1.

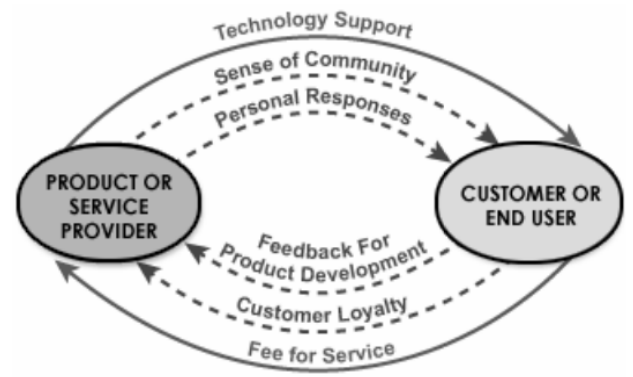

Figure 1: A value network as described by Allee [6], containing 2 participants and a number of tangible and intangible transactions

\section{C. $E^{3}$ value model}

Similar to the VNA approach, the $\mathrm{E}^{3}$ value model uses a visual notation to represent the value exchanges between different actors, though intangible exchanges are mostly neglected in this approach. "The goal of the model is twofold: a) to create a shared understanding of the various business strategies and value constellations at hand, and b) to analyze a business strategy and its operations in terms of networked value constellation for economic sustainability" [7].

Additionally, the $\mathrm{E}^{3}$-model provides a higher level of detail than VNA using additional elements such as value ports and value interfaces; value ports are used to provide or request value objects to or from its environment and are grouped in value interfaces as shown in Figure 2.

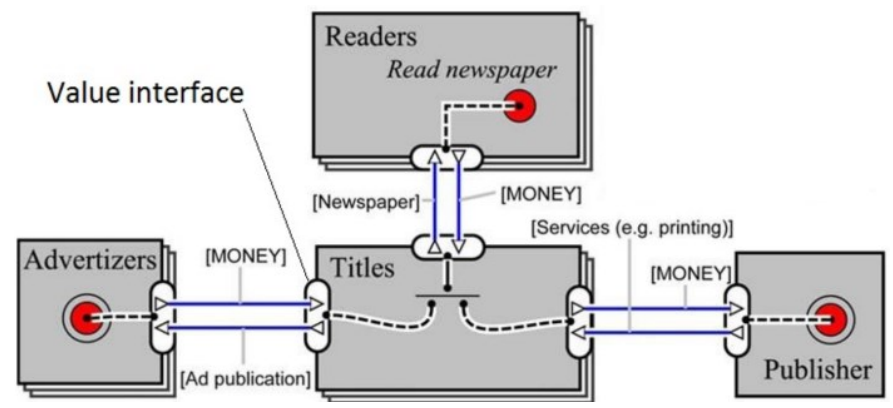

Figure 2: An example of a value interface grouping a number of value ports into value interface [7]

D. Value Delivery Modeling Language ${ }^{\mathrm{TM}}\left(V D M L^{\mathrm{TM}}\right)$

In 2015, the VDML standard was introduced. "The purpose of VDML is to provide a standard modeling language for analysis and design of the operation of an enterprise with particular focus on the creation and exchange of value" [8]. VDML groups the functionality of a lot of existing models, as shown in Figure 3, and has resulting in a total of 8 interlinked models, each with a very specific focus in order to allow for multiple perspectives (e.g. the role collaboration diagram; the value proposition exchange).

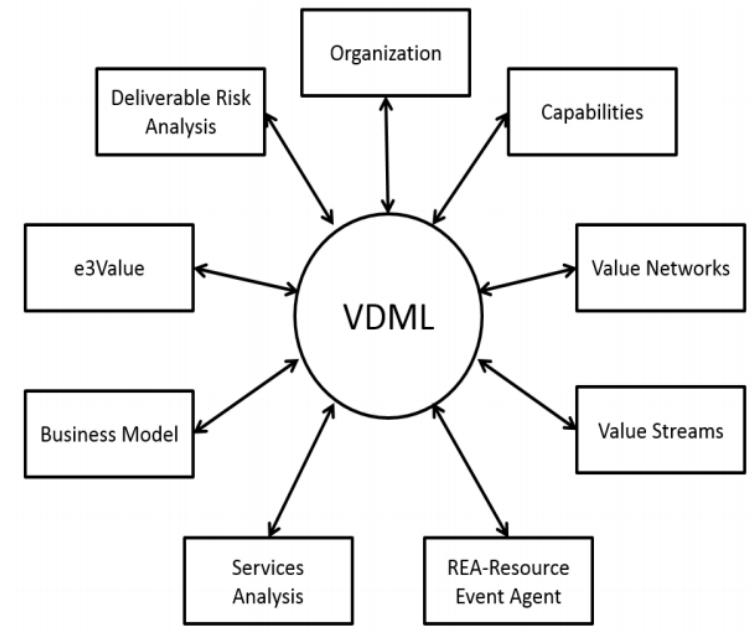

Figure 3: VDML is based upon different existing models and approaches [8]

\section{E. Dynamic Value Network approaches}

A couple of years ago, a research project was set up, approaching dynamic value networks from a very broad view [9], resulting in a set of working papers tackling various topics that are linked to (dynamic) value networks e.g. dynamic value networks for short cooperation periods [10], detection of incentives that disrupt existing dynamic value networks [11] and the link between firm behavior and the type of value network (e.g. firms as coalitions, firms that are resistant to change, ...) [12].

\section{KEY ELEMENTS OF THE DYNAMIC VALUE NETWORK ANALYSIS APPROACH}

Table 1 aggregates the key elements which were detected in the four discussed representations (BMC, VNA, $\mathrm{E}^{3}$ and VDML). From this overview, we can deduct four key elements that should be used in a value network. These are discussed in the following paragraphs; later in section IV, the concrete implementation of these parameters within the DVNmodels is discussed.

Table 1: Analysis of the most relevant models that allow the representation of value flows

\begin{tabular}{lcccc}
\hline Parameter & BMC & VNA & E $^{3}$ & VDML \\
\hline Partners & $\mathrm{x}$ & $\mathrm{x}$ & $\mathrm{x}$ & $\mathrm{x}$ \\
Tangible value streams & & $\mathrm{X}$ & $\mathrm{x}$ & $\mathrm{x}$ \\
between partners & & & & \\
Intangible value streams & & $\mathrm{x}$ & & $\mathrm{x}$ \\
between partners & & & & \\
Activities & $\mathrm{x}$ & & $\mathrm{x}$ & $\mathrm{x}$ \\
Scenario analysis & $\mathrm{x}$ & $\mathrm{x}$ & $\mathrm{x}$ & $\mathrm{x}$ \\
Economic viability & & & $\mathrm{x}$ & $\mathrm{x}$ \\
\hline
\end{tabular}




\section{A. Tanglible and intangible value streams between all partners}

As stated in [6]: "Value networks are complex. They encompass much more than the flow of products, services, and revenue of the traditional value chain'. Therefore, it is important to not only look at the tangible and thus quantifiable value streams, but also to the intangible value streams such as knowledge transfer which cannot be directly expressed in a monetary terms.

\section{B. Actors taking up multiple roles, generating external value streams}

As said in the introduction, a specific VN configuration consists of actors each taking up one or multiple roles. Each of these roles can generate value streams: both internal as well as external, both tangible as well as intangible. In contrast to the $\mathrm{E}^{3}$-model, we have chosen not to depict roles that only have internal value streams and the corresponding value streams as they do not represent a transfer of ownership, this reduces the number of elements in a model and thus simplifies the representation.

\section{Economic viability through scenarios}

Different business strategies typically lead to different value network configurations: new actors can be introduced while others can take up different roles; this changes the value streams within the network (value streams can get a different value or can be added/removed). For example, a company might have its own IT-department for IT support, or might pay an external company for this service, which can impact the economic viability of this company and the other actors within the value network.

Economic viability is determined by the actor's profitability, and calculated using all incoming and outgoing value streams from/to the actor. Being able to simulate different scenarios simplifies comparing business strategies on the long run.

As already remarked in section II, in order to be able to model the considered cost and revenues, company-specific information is required (either actual values from the past or estimated values for the future). While rough numbers can be used to provide some insights, having detailed information available will lead to more accurate results.

\section{Two type of changes within the value network}

Starting from a single VN, two types of change can be introduced:

- Structural change: an actor is added to or removed from the network, or (no longer) takes up a specific role.

- Changing value stream: either the value of an existing stream is changed, or a stream is added or removed.

Both types of change can impact the economic viability of one or multiple actors within the network; hence keeping a clear track of the value of each stream per year is of utmost importance.
IV. DVN-MODELS, A: ViSUAL REPRESENTATION OF VALUE NETWORKS IN A DYNAMIC WAY

The main idea of a DVN-model is simple enough, we define a timeline (the unit can be configured as required: e.g. months, quarters or years), upon this timeline different $\mathrm{VN}$-models can be configured as shown in Figure 4. This way, multiple configurations of the $\mathrm{VN}$ can be added on different moments in time (both in the past and the future), meaning that the roles each actor takes up can differ, but also the value of the streams can change. This way, companies can review the changes they have made in the past and analyze whether different decisions might have yielded better results and/or visualize the impact of ongoing and future business decisions on both the economic viability of the company and the direct partners.

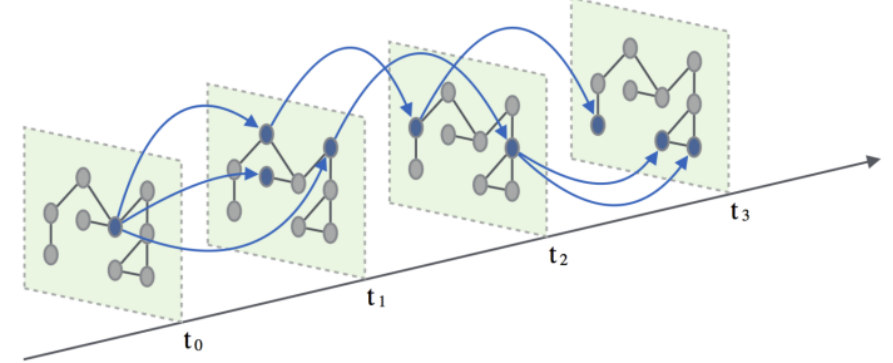

Figure 4: By mapping multiple VN-models on a time line, a DVNmodel can be made [13]

Additionally, as mentioned in the previous paragraphs, a number of key elements from other approaches have been adopted within DVN-models:

- Representation of tangible and intangible streams:

Both tangible and intangible streams are visualized within a DVN; intangible streams are represented using dotted lines, tangible ones by a full line. Additionally, tangible streams are scaled based upon the ratio between current value and the highest value over all the considered years.

○ Economic viability:

The size of the actor is scaled per year based upon its profit; the edges of the actor nodes are colored based upon a positive and negative viability (e.g. green and red).

○ Roles per actor:

The roles per actor are by default hidden to simplify the representation, as it typically makes little sense to visualize the economic viability of a role, though can be shown if wanted.

\section{Visualizing changes within the value network}

Changes in the DVN are automatically detected by calculating the delta between two sequential points in time; this opens up the possibility to include animations (e.g. an actor that is removed from the model fades away). 


\section{A. Architectural design}

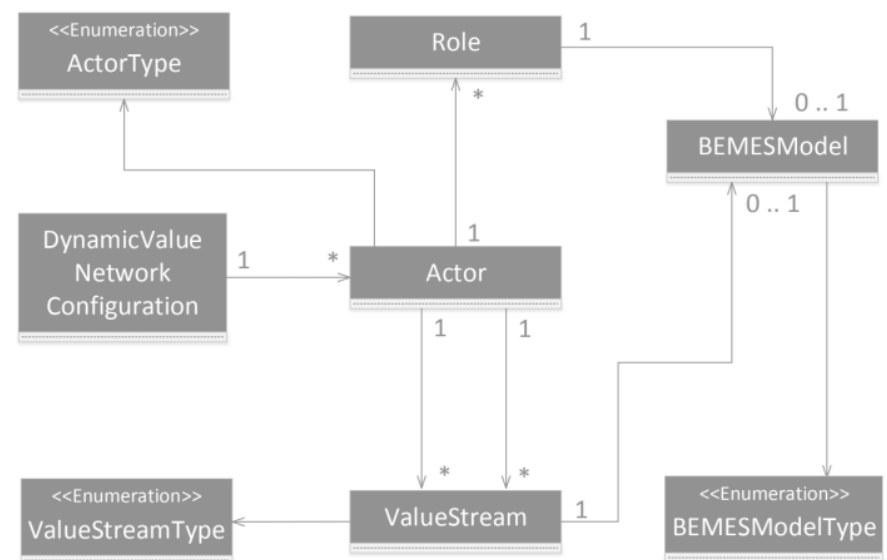

Figure 5: Suggested structural diagram for DVN-models

Currently a prototype web tool for DVN-models has been built. The exact technologies and used libraries to support this tool will not be discussed in this publication, though the architecture design can be used to re-implement the DVNapproach within other tools.

For now, the tool focuses on the visualization of internally defined DVN-models: Value streams (both incoming and outgoing) can either be fixed values or based upon cost/revenue models, as depicted by the block BEMESModel (see further)

When the web tool is requested to generate the DVNrepresentation of a model, the tool calculates for every role of an actor the total cost and revenue: the total cost is based upon the internal costs and the outgoing (tangible) value streams. Similarly, the total revenue is calculated based upon the incoming (tangible) streams.

\section{B. BEMESmodel}

Within the architecture model as shown in Figure 5; we have referred to a model type called BEMES. BEMES is a web tool currently under development at Ghent University in order to create different types of cost and revenue models (e.g. Equipment Cost Model Notation (ECMN) for hardware models, Business Process Model and Notation (BPMN) for processes costs, Physical Network Modeling Notation (PNMN) for network topology modeling, and finally revenue models). BEMES has already shortly been introduced in [14] and will not further be discussed in this publication.

\section{EXAMPLES OF DVN-MODELS}

Next, two examples of DVN-models are discussed: The first example is mainly introductory and shows the evolution of a telecom player after making a strategic change in its business model. The second example is a visualization of the business model of Netflix which has gone through a number of major changes in the last decade.

\section{A. Introductory example from the telecom world} Telenet

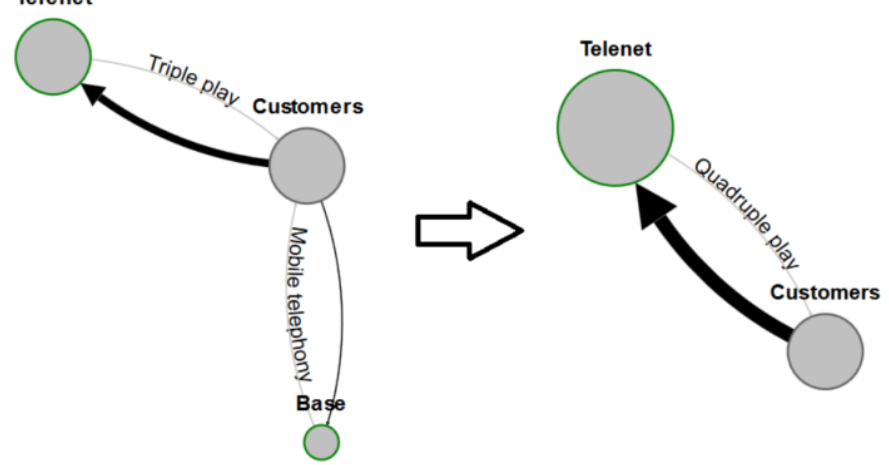

Figure 6: Example of a DVN-model with two points in time, including all key elements

The first example is basic, showing two points in time, though all of the key elements, as discussed in section III, are represented (Figure 6). The example is real Belgian example from the telecom world, which happened in 2015/2016: in the DVN we see an operator offering triple play bundles (fixed telephone line, TV and broadband internet access), Telenet, absorbing a mobile network operator, Base, allowing a quadruple play offer afterwards. The representation includes all key elements:

- Value streams are weighted (the payment increases from customers to Telenet), showing the evolution of the incoming stream. (No intangible streams such as user satisfaction are considered in the model).

- Economic viability of the telecom operator increases and is positive (and is hence colored with a green border).

- Telenet has absorbed an additional role (allowing mobile telephony), though is not represented explicitly.

\section{B. Visualizing the business model of Netflix during the last decade}

The telecom example provided a first look at DVN-models based upon two points in time. The second example shows the DVN representing the many changes Netflix has gone through from 2007 to 2016 .

We start of in 2007 (Figure 7): back then, Netflix was a content deliverer; it paid licenses to use content from content providers to offer it to their customers and used third-party CDNs (Content Delivery Networks) to facilitate the online streaming. 


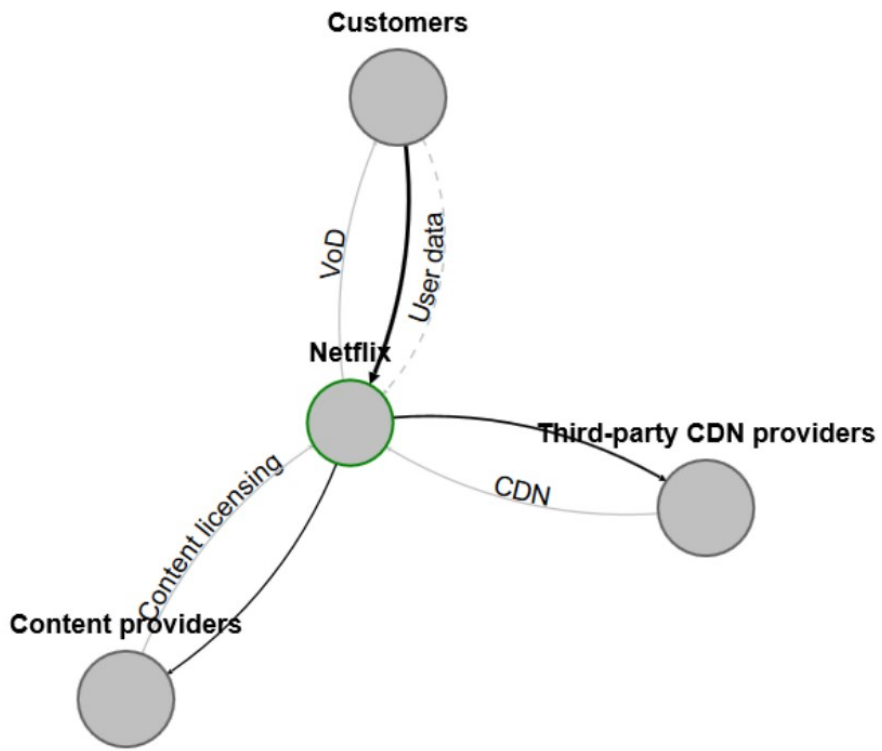

Figure 7: The initial version of the value network of Netflix in 2007

In 2008, the first major change happened; Netflix started moving to the Amazon cloud both for computational power and for storage. As seen in Figure 8, the actor Amazon has been added to the DVN, for which a monetary stream is added in return.

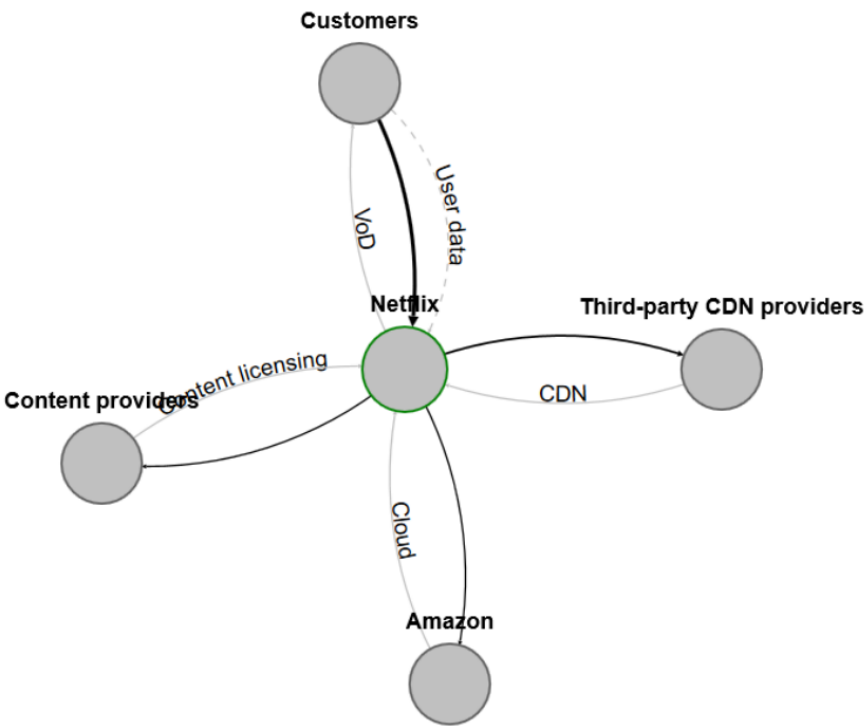

Figure 8: Starting in 2008, Netflix started relying on Amazon for both storage and computational power

The next two major steps only happened 4 years later in 2012 (Figure 9): in order to further extend the amount of offered content, Netflix started creating own content, expecting this would lead to lower costs in the long run when compared to paying for licensed content. For this reason, Netflix started working with content producers to create the so-called Netflix originals. This is represented by the new actor content producers. Additionally, in 2012 Netflix started rolling out their own $\mathrm{CDN}$ in order to reduce the fees they were paying third-party CDNs. This change is not directly visible (as this is an internal role for Netflix and thus by default hidden), though will be visible by higher profits in the long run.

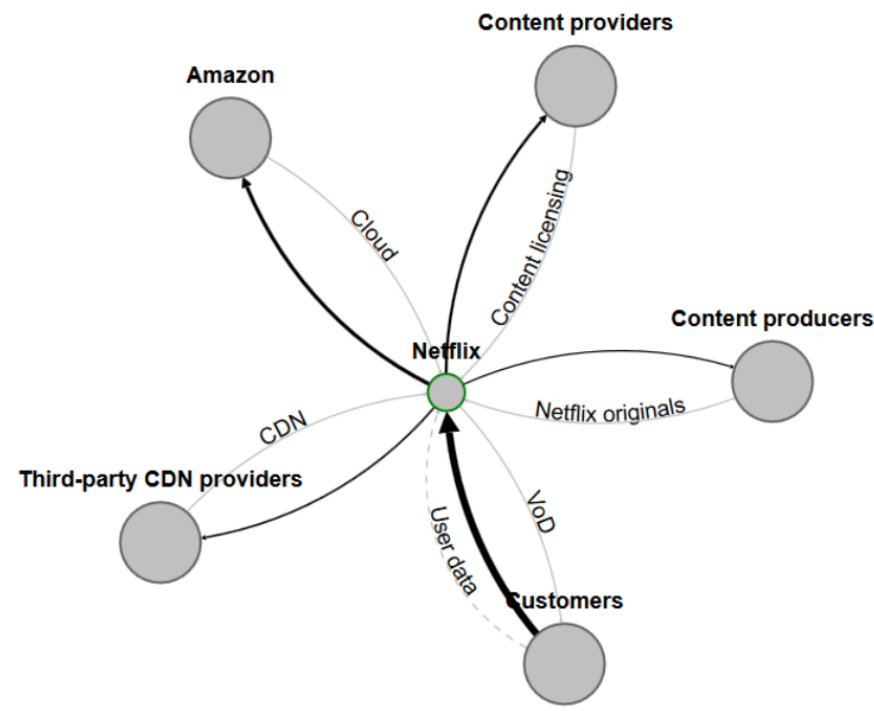

Figure 9: In 2012, Netflix teamed up with content producers to provide Netflix-specific content

From 2012 to 2015, no structural changes occurred at Netflix, though the profit kept rising (more users starting to use video streaming services), and Netflix invested further in its own content. The fees Netflix is paying for third party CDNs are further decreasing (though as the value streams are small compared to the other streams in the network this is not well visible).

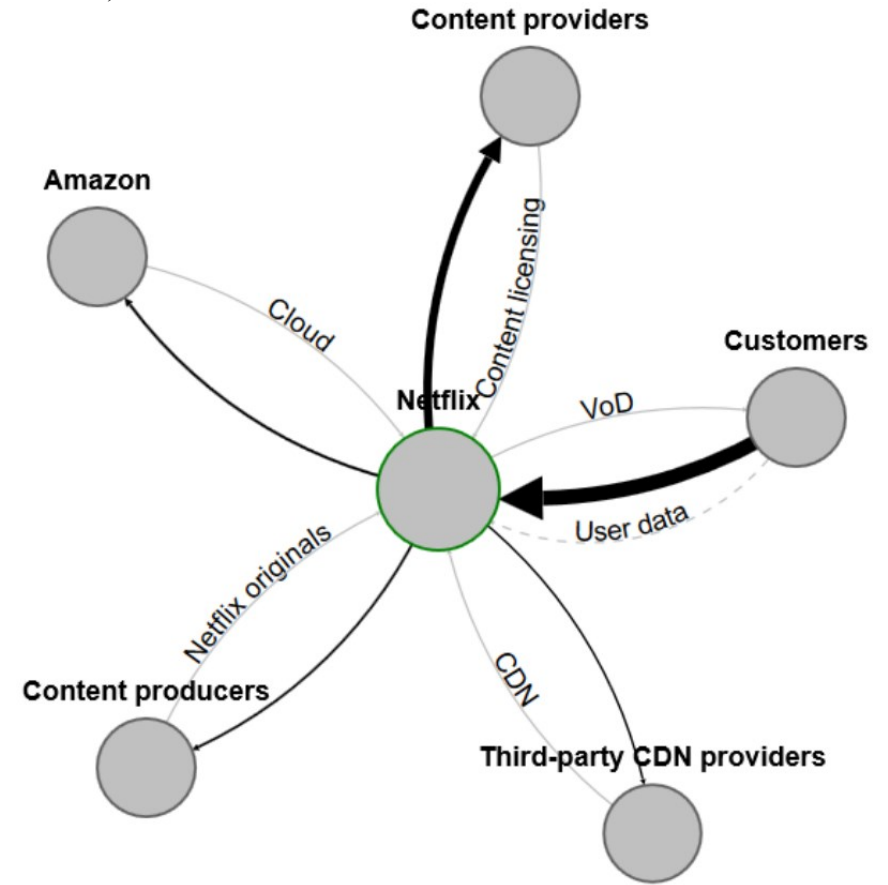

Figure 10: From 2012 to 2015, Netflix' profit keeps increasing, so is the value stream from Netflix to the content providers.

Finally, in 2016, after 4 years of preparation, Netflix was ready to rely entirely and solely on its own CDN, so the third- 
party CDN actor is no longer relevant and thus removed in the DVN as shown in Figure 11.

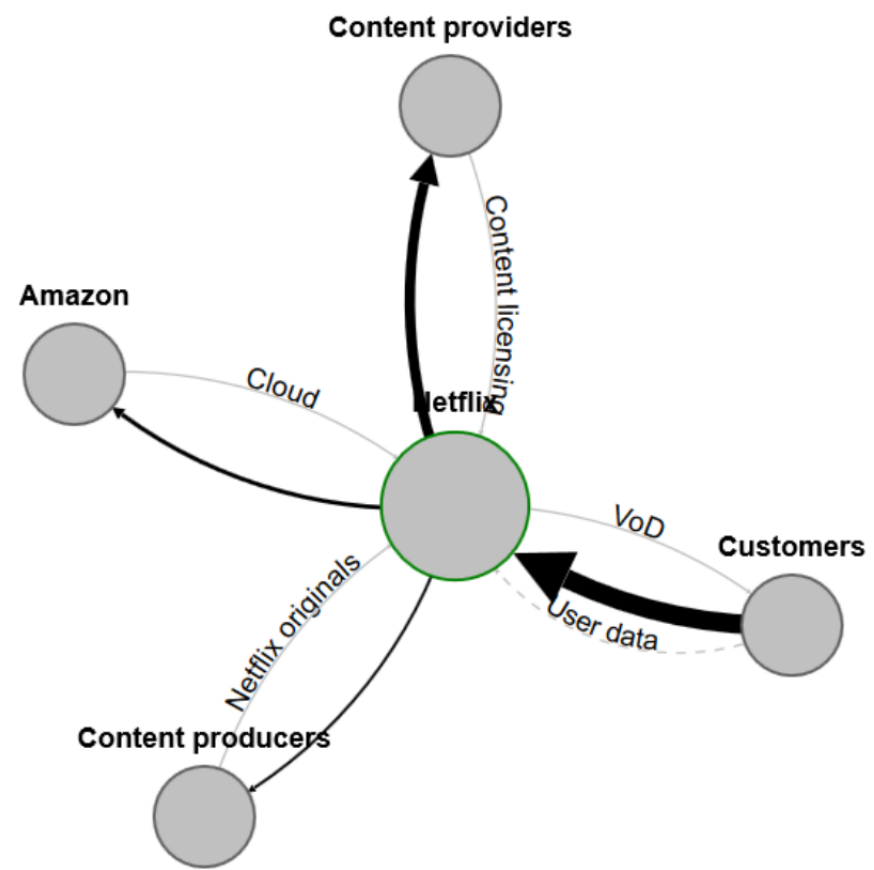

Figure 11: Finally, in 2016, Netflix has moved all its own CDN to the Amazon cloud and no longer relies on third-party CDN providers

This representation is also available online as an animation, showing the DVN year per year from 2007 up to 2016 at following link:

http://www.technoeconomics.ugent.be/research/papers/2017/ct te spruytte/

\section{SUMMARY AND FUTURE WORK}

The Internet has transformed many businesses and has introduced much more competition in various markets; this is especially the case for the telecom world. In many of these markets, the only way for companies to survive is by reinnovating their own business model or by implementing new business strategies over and over again. Realizing this kind of changes, may also impact collaboration with key partners. Cooperating typically means the exchange of services, goods, services, money or knowledge. In order to visualize these exchanges (value flows), value networks are created. In this publication, we have defined the concept of a dynamic value network (DVN) configuration and suggested a uniform representation, based upon a time-oriented approach. This approach is based upon a literature review of the most common approaches to identify and visualize interactions between partners from which the key elements have been extracted to combine into the DVN-approach. Typical representations such as VNA and the $E^{3}$-model lack dynamic/time-oriented capabilities, which is the strong suit of a DVN: changes in the VN configuration (both structural and changing value streams (both tangible and intangible)) can be defined for a specific moment in time which will help companies to estimate the impact of future business decisions or review the changes made in the past and verify whether different decisions made have yielded better results.

This approach has also been implemented in a prototype tool to test and validate the current approach, in which a number of use cases have been implemented.

Finally, as the current implementation of the DVN-models seems most promising, a number of tracks for future work have been defined:

- Simplifying scenario comparison: by comparing different scenarios for each point in time, the optimal business strategy could be chosen (e.g. for the case discussed in section $\mathrm{V}$, the optimal moment in time could have been searched for Netflix to switch over to the Amazon cloud)

- Sensitivity analysis on top of DVN-models would allow for an even better analysis of different scenarios but would also extend the current approach for a level of risk analysis.

\section{REFERENCES}

[1] W. McCarthy, "The REA accounting model: A generalized framework for accounting systems in a shared data environment," Account. Rev., vol. 57, no. 3, pp. 554-578, 1982.

[2] M. Rother and J. Shook, "Learning to See: Value Stream Mapping to Add Value and Eliminate Muda (Lean Enterprise Institute)," Lean Enterprise Institute Brookline. 2003.

[3] L. Cherbakov, G. Galambos, R. Harishankar, S. Kalyana, and G. Rackham, "Impact of service orientation at the business level,” IBM Syst. J., vol. 44, no. 4, pp. 653-668, 2005.

[4] A. Osterwalder, "The Business Model Ontology - A Proposition in a Design Science Approach," Business, vol. Doctor, pp. 1-169, 2004.

[5] A. Osterwalder and Y. Pigneur, Business Model Generation: A Handbook for Visionaries, Game Changers, and Challengers. 2010.

[6] V. Allee, "A Value Network Approach for Modeling and Measuring Intangibles," Conf. "Transparent Enterp., no. November, pp. 25-26, 2002.

[7] J. Gordijn, M. Petit, and R. Wieringa, "Understanding business strategies of networked value constellations using goal- and value modeling," in Proceedings of the IEEE International Conference on Requirements Engineering, 2006, pp. 126-135.

[8] About the Value Delivery Modeling Language Specification Version 1.0", Omg.org, 2017. [Online]. Available: $\quad$ http://www.omg.org/spec/VDML/1.0/. [Accessed: 08- Nov- 2017].

[9] D. Networks, "About Us", Dynamicvaluenetworks.com, 2017. [Online]. Available: http://www.dynamicvaluenetworks.com/about-us.html. [Accessed: 08- Nov- 2017]. 
[10] J. Peltonen, H. Tuomisaari, J. Karjalainen, T. Nyberg, and G. Nyman, "Examining the foundational properties of dynamic value networks," in Proceedings of 2013 IEEE International Conference on Service Operations and Logistics, and Informatics, SOLI 2013, 2013, pp. 484487.

[11]K. Hulkko-Nyman, G. Nyman, M. Nelson, and T. R. Nyberg, "Incentives in dynamic value networks Challenges and a theoretical research proposal," Proceedings of 2013 IEEE International Conference on Service Operations and Logistics, and Informatics, 2013.

[12] G. Nyman, M. Nelson, J. Peltonen, T. Nyberg, X. Shang, and G. Xiong, "Behavioral theory of the networked firm in value network environment: Foundations and a preliminary approach," Serv. Oper. Logist. Informatics (SOLI), 2013 IEEE Int. Conf., pp. 478-483, 2013.

[13]K. Benzi, B. Ricaud, and P. Vandergheynst, "Principal Patterns on Graphs: Discovering Coherent Structures in Datasets," IEEE Trans. Signal Inf. Process. over Networks, vol. 2, no. 2, pp. 160-173, 2016.

[14] J. Spruytte, M. Van Der Wee, S. Verbrugge, and D. Colle, "Introduction of BEMES, a webtool to simplify business process and equipment cost modelling," in BMSD 2016 Proceedings of the 6th International Symposium on Business Modeling and Software Design, 2016. 